\author{
UK Centre for Creative Writing Research Through Practice, \\ University of Wales, Bangor
}

\author{
Graeme Harper
}

\title{
A State of Grace?: Creative Writing in UK Higher Education, 1993-2003
}

1

The word 'grace' is fairly rare here in the early 21 st Century. In its classical context, the word refers to 'elegance and beauty' and qualities of 'charm', to a 'sense of propriety', as well as to 'mercy' and 'clemency'. That said, its rarity in our increasingly secular Western world is most likely related to its religious connotations - because this is a word that carries with it an association with 'finding favour' with a God or gods.

The notion of 'higher learning' also carries with it such an association with grace; that is, with sanctification. This is immediately obvious in the architecture of the world's most prestigious universities - what Westerners might call, quite without irony, 'cathedrals of learning'. It would be safe to say that the most prestigious tertiary education institutions continue to declare their higher learning ideals with architecture suggesting piety, sanctity, sublimity and, indeed, their desire to confirm academe's grace. It would be equally safe to say that most creative writers, certainly those working in Western universities and colleges, have much less association with a God, or with gods, than did their ancestors. And yet, creative writing is today a subject more associated than ever with formal higher learning. Suffice it to say that, here in Britain, though Creative Writing is more at work within the cathedrals of learning than in any previous century, the subject is yet to find its academic 'state of grace'.

The growth of creative writing in the UK in the period 1993-2003 has been phenomenal.

Much of this has been generated by two things: the founding of the 'new universities' - those polytechnic institutions 'renamed' as universities in 1992-3 and thereabouts - and by the general decrease in student applications for what might be called 'traditional' English Literature degrees. Not to say English Literature, as a subject in British tertiary education, has entirely lost its ground. However, the impact of Cultural Studies, Media Studies, Gender Studies and various other developments, amalgams, and off-shoots, has taken its toll on single honours Literature study, particularly in the less traditional UK institutions. 
Combined with these two key factors, applicants to UK higher education courses in Literature and Literature-related subjects have increasingly cited the empowerment Creative Writing provides for them when dealing with canonical notions of what should or should not be read. We might call this a 'culture change' or, perhaps more accurately, a change in how we understand our relationship with 'culture'. Suffice it to say, Creative Writing, a subject that has existed informally in UK universities and colleges since the foundation of higher learning (much as it has in all institutions of higher learning, worldwide), has become increasingly part of the formal UK university system. In the past ten years this has happened to an extent that few other Arts and Humanities subjects, if any, can equal.

Today, there are over 140 courses in the UK where undergraduates can focus on Creative Writing. There are over 70 Masters courses. And there are around $20 \mathrm{PhD}$ programmes in Creative Writing. This, however, is only the half of it because the figures largely do not take into account short courses, the constantly changing stream of Continuing Education courses, or 'Further' Education developments, which are in addition to those in 'Higher' Education. They also don't acknowledge the 'single module' growth that has occurred in both likely, and quite unlikely, places. Over the past ten years Creative Writing modules have found their way into a remarkable number of Literature, Media, Film, Theatre, Communications, Art and Design and Music degree schemes, but they have occasionally also formed some part of the growth of such university courses as those in the Medical Humanities, Psychology and Education.

In 1996 we set up a national database to record this growth - the 'UK National Creative Writing in Higher Education Database'. For the first few years this database was maintained and updated using 'paper' questionnaires. However, the rapid growth rate demanded more technological input! The database went electronic in 1998 and, in 2001, a UK national committee was set up to manage its development. This committee included key input from the Arts Council of England, particularly their funding of a database update, and the assistance of a parttime researcher.

The UK National Committee on Creative Writing in Higher Education currently consists of representatives of the Arts Council of England, the National Association of Writers in Education (NAWE), Writernet, the British Council, the English Subject Centre and the UK Centre for Creative Writing Research Through Practice. However, we plan to invite others to join and don't in any sense see this committee as 'exclusive'.

The national database, now augmented with input from NAWE's own database, and from databases developed by the British Council and others, is managed on our NAWE website at http://www.nawe.co.uk It provides anyone interested in creative writing in UK Higher Education with the most up-to-date information on courses and institutions offering Creative Writing. It should be noted, however, it does rely on institutions updating their own information, and with such rapid and widespread growth this is not always that simple.

Being 'not always that simple' could be taken as the key theme for Creative Writing in UK universities and colleges over the past ten years. Three 'not simple' problems have featured. 
Firstly, where Creative Writing has grown, more full-time university and college work has been offered to UK-based creative writers; however, the subject continues to depend on a considerable body of part-time staff staff that are not always well supported by institutional pastoral mechanisms. Neither is the subject well resourced, generally, in terms of capital or physical needs. Creative Writing is often seen as comparatively inexpensive in UK academic terms, and this naturally has knock-on effects. In some quarters, the idea that creative writers should feel 'privileged' to have employment at all in Higher Education prevails, as does the notion that teaching creative writing should not draw greatly on institutional 'back-up'. Stick a creative writer in a room for a few hours a week and you have a degree programme...or, at least, the cynical among us might suggest this is one common attitude. Which points to a second problem: the general failure of British academic research bodies to recognise that the subject exists to the extent that it does, and to realise that, as a subject, Creative Writing has important and specific research and development needs.

The Arts and Humanities Research Board (AHRB) is the key Arts and Humanities research funding body in the UK. Its work is complemented by that of the British Academy and, to a lesser extent, that of the Leverhulme Trust. The AHRB, formally the HRB (the Humanities Research Board), has struggled to place Creative Writing within the context of British academic research. Evidence of this struggle is far too plain.

For example, at first Creative Writing was not an eligible subject for the AHRB scheme 'Small Grants in the Creative and Performing Arts'. It was not eligible because it had been placed by the AHRB in a research assessment panel labelled as 'English Language and Literature'. This panel was classified as a 'Humanities' panel. Creative Writing was, thus, formally said to be a 'Humanities' subject and therefore was not able to access 'Small Grants in the Creative and Performing Arts' . This anomaly has now been addressed. But others remain - not least the almost entire absence of AHRB scholarship support for postgraduate study in Creative Writing, and the general lack of input from other research bodies to supplement the work of the AHRB. Another key problem is the composition of funding body assessment panels.

While it is true that many of the AHRB's English Language and Literature panel are, and have been, experienced critics of Literature, at best only one member of each 7-12 member English Language and Literature panel has had creative writing experience. There is yet to be an appointed member of this panel who has qualified in Creative Writing at university and combined that with a successful creative writing career. Such an absence in such a key research funding organisation is very telling.

It must be said, however, the AHRB has been the first to admit that it has not yet got right the funding of creative writing in universities and colleges. The problem of developing a research and development strategy with UK academic research bodies would seem to be a matter of communication rather than of confrontation. Namely, there continues to be, in official circles, very little understanding of the nature of Creative Writing teaching and research. For starters, there is next to no understanding of the degree to which creative writers have developed ideas, attitudes and perspectives on the relationship between 'creative practice' and 'critical understanding' and there is next to no recognition in 
academic funding circles of the ways in which the subject has developed its apparatus for discussion, debate and development. Much of this has to do with the history of the subject on UK campuses.

Some background might be useful.

Creative Writing is often seen to have formally entered UK Higher Education in the 1970s with the emergence of the MA course at the University of East Anglia (set up by Malcolm Bradbury and Angus Wilson). Others note the establishment of a Masters degree at the University of Lancaster. Still others point out that from the 1960s onward there were tertiary education institutions in the UK - at that time not yet 'renamed' universities - who were keenly using what we would today consider Creative Writing teaching and learning as a way 'into' literature for students who were not, perhaps, as far up the academic food chain as their university-bound counterparts.

Of course, the first great danger of seeking to achieve a state of grace is an over-emphasis on long term piety. And the second great danger is undue concentration on proving propriety. Thus a concentration on 'first-ism' might not ultimately be very useful.

And yet, the University of East Anglia MA course has most certainly been an important one in the UK, in part because its first student, Ian McEwan, is now an internationally successful fiction writer and screenwriter. And, even more so, because Malcolm Bradbury (later Sir Malcolm) became an outspoken and generous supporter of Creative Writing and creative writers on campus. But this must not mask a pressing issue.

While many courses were set up from the '70s through until the '90s, many of them likewise employed a somewhat ill-defined sense of what Creative Writing education might involve; and this fluid sense, often connected with a general sense of 'coming to appreciate the canon of great literature' or connected with broadly Formalist notions of literary practice gave these courses little to build on in terms of creating the critical, aesthetic or pedagogic apparatus we would now associate in Britain with Creative Writing learning.

And then, in the 1990s, Creative Writing in UK Higher Education came of age. It did so in a way that might have been predicted, had the subject been taken seriously within general academe when first introduced. Some of this 'coming of age' can be seen in the recent growth of such UK national writing education bodies as the National Association of Writers in Education (NAWE), now boasting its largest membership ever, and by the launch of the UK Centre for Creative Writing Research Through Practice.

Drawing on a collection of critical and theoretical resources, and supporting this with now very strong formal evidence of writers who had studied at university and become successful, Creative Writing in the UK began to consider what it was about, and how it might develop further. Not only did UK writers begin to realise that the process of teaching Creative Writing involved certain kinds of pedagogic issues, methods and intentions, but that the kinds of discussions that writers undertook 'with themselves' (those in-process considerations that writers deal with day-to- 
day) could be encouraged within student bodies working in academe and must be seen as the basis of a 'subject identity' in its own right.

In this way, Creative Writing in British universities and colleges confirmed that it included, as a subject, such things as: teaching and learning about both an individual practice and a practice defined by social, cultural, political and economic conditions; discussions around authorial intention; undertaking close reading and connected hermeneutical practices; considering the role of the reader; looking at the aesthetics of a country, region or local environment; approaching forms, styles, patterns and structures, dealing with voices, sounds, dictions and tones; using and considering grammars and discourses, denotations and connotations, the literal and the metaphoric, and points of view; revising and editing.

The subject would also include work on creating distance, or more frequently ensuring a lack of it, between writer and reader; the development of writerly apparatus linked to simplicity and complexity, implication, abstraction and accuracy, repetition, parallelism and contrast, conflict and resolution, foregrounding, anticipation and delay, association, imagery, symbolism and correlation, unity and disunity, assumption and compulsion, intention and inevitability.

Not everyone, of course, got on board. Some institutions in the UK, as well as some tutors, continue today to see Creative Writing as an activity largely on campus not to 'investigate' Creative Writing but simply to 'provide' exchange between working creative writers and studying students. What makes little sense in this approach, of course, is that many writers on campus are themselves very successful 'working' creative writers and the employment of writers without them being involved in the general development of Creative Writing as a subject seems at best oldfashioned and at worst a denial of those important developmental leaps made by the subject over the past quarter of a century... Which brings me to the final problem.

Finally, Creative Writing on campus in the UK has suffered, and continues to suffer, moments of considerable 'identity crises'. While the subject has grown in formal importance, and has thus become a key financial contributor to many literature and indeed film, media, and theatre departments, it has not yet found a way to capitalise on its on-campus success, its off-campus success (which can only in part be defined by 'publication') and its determination as a recognised academic subject. Some still wonder if this subject should be dealt with by National and Regional Arts Councils rather than by Research Councils - and, indeed, the Arts Councils. As well, such organisations as the Royal Literary Fund, do play a strong role in funding visiting writer programmes and developing writing development schemes albeit, in the Arts Council case, mostly in schools and in the community rather than in universities and colleges. In addition, although models provided by other creative arts subjects particularly music, drama and film/media - have proven very useful, Creative Writing in the UK remains so strongly connected with the subject of English Language and Literature that there are tensions between 'what the subject is' and 'where it has most strongly emerged'. Indeed, some writers wonder if they are not simply backing up a decline in general student interest in English literature, rather than teaching a subject existing in its own right. Where such concerns can be countered, of course, is in the recognition of the subject's own unique concerns and foci, and in confirmation that collaboration with Departments of Literature (English 
and otherwise), as well as with other subjects, is exactly that: collaboration rather than definition.

\section{5}

The facts that currently give Creative Writing and creative writers cause for celebration in UK Higher Education, after what has been 10 years of phenomenal formal growth, are not all contemporary.

The historical facts are these: that Creative Writing is one of the oldest subjects associated with British higher learning, and that this has occurred informally as well as formally; that creative writing in English, one of the world's primary languages, does in some ways look back historically toward the UK, however tenuous that link might now be (and recognising likewise that creative writing in the UK is undertaken also in languages other than English); that many key figures in British arts and humanities Higher Education have been creative writers and that many British creative writers, whether undertaking formal Creative Writing courses or not, began their careers while students at university or college (Christopher Marlowe and Graham Greene, to name two obvious 'historical' examples).

The contemporary facts are: that Creative Writing is today one of the strongest recruiting of all Arts and Humanities university and college subjects in the UK, and one of the strongest recruiting subjects in the tertiary education sector generally; that we now have a well developed set of 'research-through-practice' discussions that allows Creative Writing and creative writers to articulate the dimensions of their subject, to defend its ideas, methods and philosophies, and to put in play strategies for assisting its development; that we have a set of organisations and bodies representing Creative Writing and creative writers in UK Higher Education, and that these are growing in membership and offering services to their members that are part of any professional practice; that we have a generally very lively student body, committed to their subject in a way many other subjects would envy; and that we recognise our individual successes as writers are only part of our place on campus - that we need also to ensure our subject is properly resourced to be a key one in making the 21 st century British campus creative.

A $\mathrm{PhD}$ creative writing student of mine pointed out recently that a state of grace is never 'achieved'; rather, it must be 'granted'. Perhaps in the strictly religious sense he is right. But on this occasion I'd like to disagree with him. The state of grace for Creative Writing in British Higher Education has never needed granting, it has simply required finding...and, if anything, the considerable formal growth of the past ten years has moved us much, much closer to that discovery.

\section{Links}

http://www.nawe.co.uk

http://www.ahrb.ac.uk

http://www.writernet.org.uk/

http://www.bangor.ac.uk/cwrtp

http://NewWriting.latest-info.com 
Graeme Harper (aka Brooke Biaz) is Director of the UK Centre for Creative Writing Research Through Practice, and the co-editor of New Writing: Tthe International Journal for the Practice and Theory of Creative Writing (MLM). He holds writing awards, grants and fellowships from arts organisations around the world, including the National Book Council (Australia), the National Endowment (UK), the Commonwealth Universities Research Board, the British Academy, the European Commission, the AHRB and the EFS (USA). He directs the MA and PhD programmes at the University of Wales, Bangor, and works as a consultant to several other university creative writing programmes. His latest work of fiction is Dancing on the Moon (Eclipse 2003) and his new collection of short stories Small Maps of the World is contracted for submission in 2004. He is currently completing a new novel.

TEXT

Vol 7 No 2 October 2003

http://www.griffith.edu.au/school/art/text/

Editors: Nigel Krauth \& Tess Brady

Text@griffith.edu.au 